\title{
Using Flashcard Games To Enhance Vocabulary Acquisition For High School Students
}

\author{
Pham Thi Kieu Oanh*, Dang Thi Thanh Dung** \\ * Foreign languages education faculty, Thai Nguyen University of Education \\ DOI: 10.29322/IJSRP.12.01.2022.p12143 \\ http://dx.doi.org/10.29322/IJSRP.12.01.2022.p12143
}

\begin{abstract}
Vocabulary is considered as the heart of language comprehension, and learning English vocabulary is an important component for all students because nothing can be conveyed without vocabulary in English communication. On the other hand, a great deal of research has recently been conducted to deal with vocabulary learning. Based on pre-research, it is found out that high school students had problems in mastering vocabulary, especially vocabulary acquisition because it requires students' capacity not only to perceive but also to use words to understand and communicate. English learners always seek for effective ways to grasp new words, but it is hard for them to store all of their English words in long-term memory. One of the most effective tools to learn English vocabulary is Flashcard which is also a commonly used study method. Notwithstanding, Flashcards are not efficiently used in learning vocabulary, so the researchers would like to optimize the uses of Flashcards and promote students' vocabulary acquisition through using Flashcard games. This study aimed to investigate a) the initial level of 10th graders' vocabulary competence at Thai Nguyen high school for the Gifted b) the difficulties which grade 10th students have to face in vocabulary acquisition c) The effectiveness of using Flashcard games to enhance grade 10th students' vocabulary acquisition. Questionnaire and Tests were used as two main instruments to collect data, and experiment was employed as the research method in the current study. In the process of the research, 40 students were chosen randomly to take part in the experiment in over 8 weeks. They were divided into 2 groups including the experimental group and the control group. For the quantitative data, the data was analyzed by finding and comparing the mean scores in pre-test and post-test. The research was expected to have a positive impact on students' vocabulary acquisition since there was an improvement in the amount of students' vocabulary after applying Flashcard games in learning and teaching English words.
\end{abstract}

Index Terms- Flashcard games, Vocabulary acquisition, Capacity.

\section{INTRODUCTION}

$I^{\prime}$ is claimed that English nowadays becomes the most widelyused foreign language in Vietnam. Particularly, English is used as an obligatory subject at almost schools across Vietnam. Generally, Vietnamese students need to experience a certain English learning process called 10-year English program from grade 3 to grade 12 throughout the whole general educational system. Students also have to gain a particular amount of vocabulary in order to learn English skills and communicate in English. This is because vocabulary is considered as a major component of language learning.

Any language learning process is incomplete without vocabulary. Learning a language would be difficult due to lack of vocabulary. English learners who want to get the levels of proficiency need to acquire thousands of words. The size of one's vocabulary has also been linked to proficiency: the bigger your vocabulary is, the more proficient in English you are. As a result, vocabulary has been proven to be one of the most important components which students have to grasp because it shows how well students read, write, and communicate in English.

However, learning vocabulary is incredibly challenging if learners have no method or tool to memorize English words effectively. Language learners always have to struggle with a large amount of words, and they also seek for ways to put all of words in their long-term memory. Moreover, remembering is not enough because students have to not only perceive but also use words in spoken or written form. Teachers also have considerable concern for what teaching methods might foster students' process of learning new words called vocabulary acquisition. Vocabulary acquisition processes are completely complex because it requires students to have capacity to comprehend all components of a word including form, meaning, pronunciation and uses. In many EFL classrooms in Vietnam, a typical approach for teaching vocabulary can be found. In Vietnam, English teachers usually write a list of new English words which include in the lesson on the board at the beginning of the lesson, and they provide Vietnamese translations of those words, and ask the whole class to repeat the words several times. Teachers just emphasize single words, which are often chosen intuitively or based on glossaries in textbooks and reference books. Therefore, teachers need to have alternative ways and techniques in order to enhance students' enthusiasm in learning language, especially vocabulary.

One of the most effective tools to learn English vocabulary is Flashcard which is popular with most of learners. Flashcard stimulates students' brain creation to remember English words effortlessly. Although Flashcards are commonly-used among students, the effectiveness of student-created Flashcards in the classroom is unclear. Students just normally use Flashcards to learn new words, but they do not even know that there are numerous activities using Flashcards to help them learn English vocabulary more effectively. In addition, Flashcard is a common tool for all students to study vocabulary, but it is rarely used to organize games in classroom. For these reasons, to promote the uses of Flashcards in developing students' vocabulary, Flashcard 
games are considered to be efficient activities to teach new words in classroom. In field of foreign language, Flashcard games haven't been precisely implemented, and not many previous researchers have studied about this problem. Therefore, the researchers expected to conduct successfully the study named "Using Flashcard games to enhance vocabulary acquisition for high school students".

\section{LITERATURE REVIEW}

\section{Vocabulary acquisition}

There is a great deal of research which has been conducted to account for the definitions of vocabulary acquisition. Vocabulary acquisition is part of the psychology of secondlanguage learning which has been neglected in recent studies (Paul Meara, 2008). Most learners readily admit to have significant difficulty with vocabulary, and once they have progressed past the initial stages of learning their second language. Vocabulary acquisition is believed as the biggest obstacle towards students while learning foreign language. When learning a new language, vocabulary acquisition refers to how people increase the quantity of words they know.

Laufer (1991) identified five distinct categories in the process of learning vocabulary, often known as vocabulary acquisition. The first category is form, which is the ability to recognize a word in both aural and written settings, as well as the ability to pronounce and spell the word. Word structure is considered as the second category which refers to the morphemes (free or bound) and derivatives that make up a word. Third, syntactic behavior is discovered, which describes how a word functions in a phrase and what lexical implications must be considered while using the designated term. Meaning is the fourth category, which comprises referential meaning (homonyms, polysemes, idioms, and so on), emotive meaning, and pragmatic meaning. The final category is lexical relations, which refers to understanding a word's relationship to other words and their meanings (synonymy, antonymy, hyponomy), as well as collocations. The researchers had a solid foundation to conduct the study based on the different perceptions of vocabulary acquisition. Therefore, vocabulary acquisition can be defined as a process of learning new words by which one acquires the capacity to perceive and use words to understand and communicate.

\section{Approaches to learn English vocabulary}

Learning words in context vs. learning words out of context. Many language specialists believe that contextualized vocabulary learning is more successful than memorizing terms from lists. While decontextualized learning (word lists) may assist students retain vocabulary for tests, Oxford and Scarcella (1994) find that children are more prone to lose terms memorized from lists. McCarthy (1990) claims that a word is best digested and retained when it is taught in a relevant context. Furthermore, current evidence on vocabulary acquisition shows an increase in support for explicitly teaching words out of context at an early stage of language acquisition, with more context-based vocabulary learning occurring later in language development (Coady, 1997b; Meara, 1997; Nation and Newton, 1997). This method combines contextualized reading with decontextualized vocabulary learning. According to two research, learning that includes both contextual reading and explicit vocabulary instruction leads to significantly larger gains in vocabulary knowledge than contextualized reading alone (Paribakht and Wesche, 1997; Zimmerman, 1994).

It cannot be denied that learning vocabulary out of context is hard to understand and remember words. In this research, the researchers used Flashcard in different games and contexts to help students perceive as many forms and uses of a word as possible.

\section{Flashcard usage in learning and teaching}

The usage of Flash cards is one method for learning vocabulary. A Flash card is a piece of cardboard with a word, a sentence, or a basic image printed on it. Flashcards usually have words on one side and pictures or definitions on another side. When teaching vocabulary, both sides of the Flash card should be used. Cross (1991) defined a Flashcard as a basic piece of card or paper including two sides which is the most extensively used as visual aid in language class. According to the definitions above, Flashcards are cards containing a word or words, a number, or an image on them that are used in the classroom by teachers and students to help them learn and memorize new words. One of the biggest benefits of Flash cards is that they can be taken practically anywhere and studied whenever you have a spare moment (Brown, 2000).

Haycraft (1978) stated that there are two types of Flashcards including word Flashcards and picture Flashcards. Word flashcards are cards on which words have been printed in both sides of Flashcards while picture Flashcards have a picture on one side which demonstrates the word. Word flashcards can be classified into different kinds which are gapped sentences, synonyms, antonyms, definitions, translations. In this study, the researchers conducted Flashcard games in classroom through using both word Flashcards and picture Flashcards. Especially, word Flashcards were used regularly rather than picture Flashcards because word Flashcards can be used to design many drills for students to practice new words.

\section{Types of Flashcard games}

We cannot deny the significant contribution of flashcard in learning vocabulary, but we can also create a number of games based on Flashcards to stimulate students' interest in learning English vocabulary and also boost their brains' memories. Flashcard games can be defined as the activities and drills which are designed based on the combination of Flashcards. On the other hand, games can help learners improve their problem-solving skills and boost their self-esteem and confidence. When properlyorganized, games can also provide a learner-centered environment and good possibilities for socialization, as well as arouse people's drive to win and compete. Therefore, the use of Flashcard in organizing games is an effective way for teachers to teach new words, and students can also use Flashcard games to learn new words individually or practice with their classmates.

The types of games using Flashcards are not restricted because it depends on the creation of users, but basically there are four major kinds of Flashcard games.

Words guessing

One of the most effective activities involved in Flashcard is guessing words based on their definitions or related pictures. Students can make their own Flashcards by writing the meaning 
of the words on the back of the cards. Then, they could put these cards with the word facing down and the meaning facing up. Students read the meaning of the word and guess. By doing this, students can check the meaning and remember the meaning of new words. Teachers can also organize many activities, particularly the game named "Do you know?" Students can be divided into small groups. Each group has a leader who has responsibility to describe the words without involving the letter or the name of the vocabulary, and other members of group can guess the exact words.

\section{Words matching}

The first activity is called "synonym matching" which will help students learn more vocabulary. Students write down all of the words that they have recently discovered on a piece of paper. After that, the students get them to write synonyms of each of these words, beside the new words that they have learned. Therefore, not only are they learning one new word, they're learning an additional new word that is a synonym. Synonym is extremely important not only for writing and speaking but also for reading and listening too. The students cut up these new words to make a set of Flashcard. Moreover, one side of Flashcard must be a new word, and another side can be a definition, a picture or a synonym. Antonyms can be used as same as synonym activities.

"Finding around" is a different game. By learning the traits and features of the language provided, this game increases students' comprehension of the vocabulary. The pupils are divided into groups of 3-5 students by the teachers. Each group is given a different sheet of paper with 5-7 descriptions of items on which the students must subsequently identify the names of the vocabulary by matching the descriptions to the pictures or flashcards (which include the written forms) displayed around the classroom. The winner will be the first group to complete the job with accurate answers. The answers demonstrate a high level of language mastery.

\section{Words classification}

In this activity, students need to have a set of Flashcards including a large range of vocabulary. Students then can categorize the words by topic and word form including noun, adjective, verb and adverb. Categorization really helps students' brain remember and use these words effectively. There are many activities that teacher can do to enhance students' attention and interest in learning new words. Teachers can divide the class into different groups and hand out them sets of Flashcards. After that, teachers stick a table on the board which includes different categories of topic or word forms, and ask students to discuss in groups to classify the words and stick on the table.

Storytelling

One of the activities that can be used to teach vocabulary to young learners is storytelling. Stories give a rich imagined world, formed by the language, which allows learners to engage and enjoy as they learn language (Cameron , 2001). In the storytelling activity, the teacher gives students a set of Flashcards and asks them to read the meaning of words to create a short story that uses these words effectively. Students could practice their speaking doing this, or they could practice writing doing this. The thing is students just have to know the meaning of the words and how to use them in a sentence.

\section{Previous studies}

There are numerous studies related to Flashcards in the world, but it is not true for Flashcard games. Nevertheless, almost studies which have been accomplished showed that Flashcards are excellent English teaching tools for teachers to introduce new words and drill practice. Tuite et al. (2012) employed the study on a Facebook game named Picard. It is a fun and effective tool using Flashcard for learners to memorize words in various fields, because Picard provides input from players using their own mnemonic devices, as well as a social environment for players to communicate and help each other learn and stay motivated. Moreover, Baleghizadeh \& Ashoori (2011) carried out research concerning the impact of using Flashcards compared to word lists on students' learning of English vocabulary. The result of their study indicated that Flashcards could lead to better learning than word lists.

In Vietnam, a few research papers have been conducted to deal with the innovative ways to learn and teach vocabulary involving Flashcards. First, Tran Thi Ngoc Yen (2019) investigated the impacts of Flashcards and word lists as vocabulary instructional techniques on EFL learners' vocabulary retention. Unlike prior studies that solely looked at learners' retention of meaning, this study looked at both meaning and spelling retention. The findings showed that flash cards overweight word lists for EFL learners in primary school, but word lists outperform Flashcards for older learners in elementary and pre-intermediate levels. Also, Thi Thu Huong Ho (2019) carried out a study on the effectiveness of digital Apps to enhance receptive vocabulary acquisition of Vietnamese EFL learners. To be more precise, a case study was implemented to compare the uses of Quizlet and Paper Flashcards.. In terms of the language environment given for learning and meeting students' preferences, Quizlet has some advantages over paper flashcards. However, paper flashcards offer several distinct advantages over Quizlet, such as encouraging pupils to practice speaking words.

\section{RESEARCH METHODOLOGY}

In this research, the researchers employed the quantitative research as the major approach for data collection. According to Leedy and Ormrod (2001), quantitative research is clarified through survey and experimentation since it builds on existing hypotheses. The researchers mainly used the experimental research to examine the differences between the two characteristics of the study group.

The participants in this study were chosen via simple random sampling. They included a total of 40 students in the $10^{\text {th }}$ grade at Thai Nguyen high school for the Gifted. They are all from 14 to 15 years old during the academic year 2021-2022. The students were divided into two equal groups: the experimental group, which used Flashcard games to learn English vocabulary $(n=20)$, and the control group, which can use Flashcards but not be taught to play games using Flashcards $(n=20)$.

In this study, the researchers employed two main data collection instruments including questionnaire, and test. First, the questionnaire is a method for gathering quantitative data that is extensively used in construction research because it is an effective research tool for obtaining standardized data. In this research, the 
researchers gave students the questionnaire to investigate the current situation of high school students in learning English vocabulary and their attitudes towards Flashcards. Also, in this research, the researchers would conduct both pre-test and post-test to compare the difference between control group and experimental group in vocabulary acquisition. The result of the test also reflects the improvement of students' vocabulary acquisition in experimental group.

Microsoft Excel 2010 and SPSS 20 were both employed to draw conclusion whether there is an improvement in students' vocabulary acquisition after using Flashcard games.

\section{FINDINGS AND DISCUSSION}

\section{The current situation of students' vocabulary acquisition}

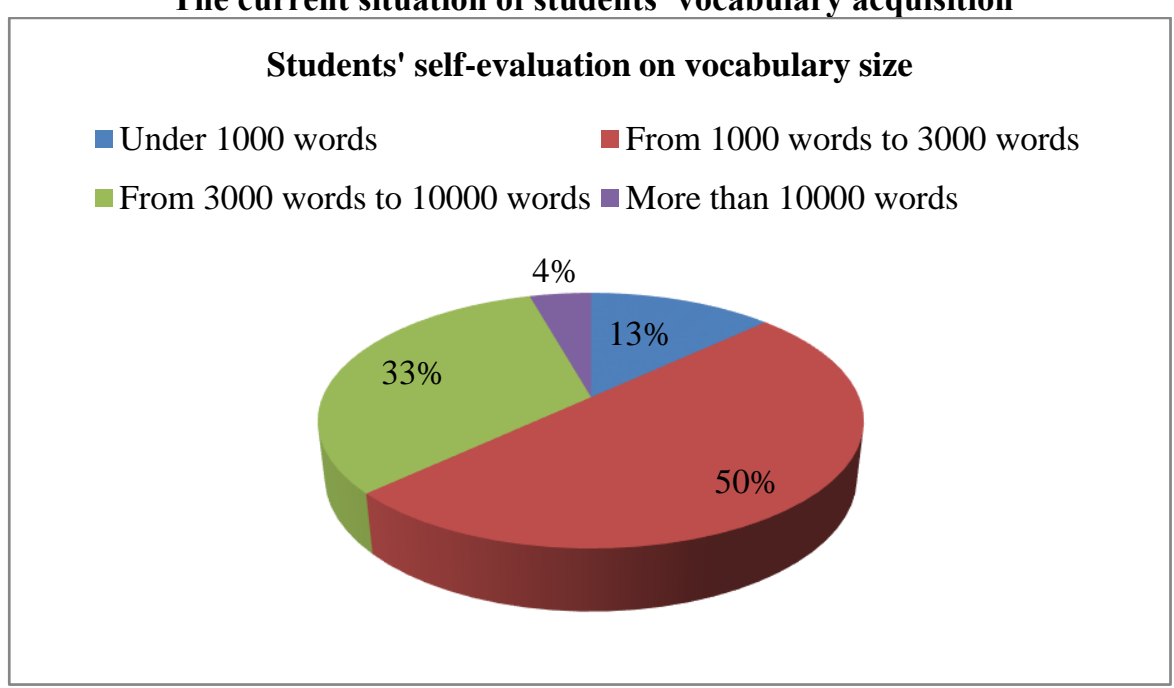

Figure 1. Students' self-evaluation on vocabulary size

The pie chart illustrates the percentage of students' vocabulary size which has been estimated based on students' experience and the result of the test on the website named "Vocabularysize.com" by Paul Nation. As can be seen from the figure, a half of students had the vocabulary size from 1000 words to 3000 words. This means that a person with a receptive vocabulary of the 2000 most common word families can understand $90 \%$ of the words in spoken texts (Nation, 2006). The proportion of students' vocabulary size from 3000 words to 10000 words accounted for $33 \%$, and this figure showed that students who have receptive knowledge of the most common 3000 word families are better able to comprehend real reading materials in the language they are studying (Laufer , 1992). 13\% of students obtained under 1000 words, so these students still lack vocabulary to comprehend English. Meanwhile, just only $4 \%$ of students got their results for obtaining more than 10000 words. It is clear that almost students have enough fundamental vocabulary to understand when they read and listen to English. Nevertheless, the students still need more practice to expand their lexical resource.

\section{Students' habits of learning English new words}

$\square$ Percentage of students

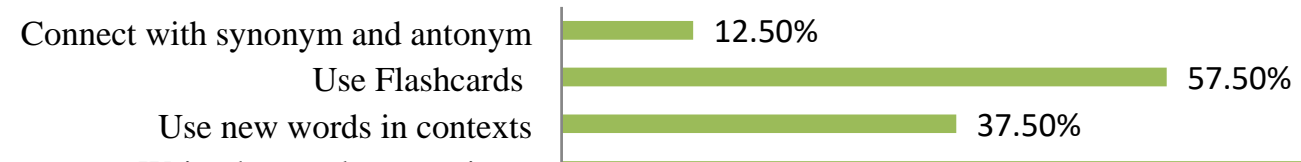

Write the words many times Read the words aloud many times

\section{Figure 2. Students' habits of learning English new words}

The bar chart reveals the percentage of high school students' habits in learning English vocabulary which was analyzed based on five categories. The most popular way to learn new words was writing the words as many times as possible which represented
95\%. Similarly, reading words for many times also accounted for a very large majority about $87.5 \%$. $57.5 \%$ of students chose Flashcards to record their new words and used them as a tool to learn English vocabulary. The proportions of students who often 
use new words in contexts and connect words with synonym as well as antonyms to memorize words were under $50 \%$, at $37.5 \%$ and $12.5 \%$ respectively.

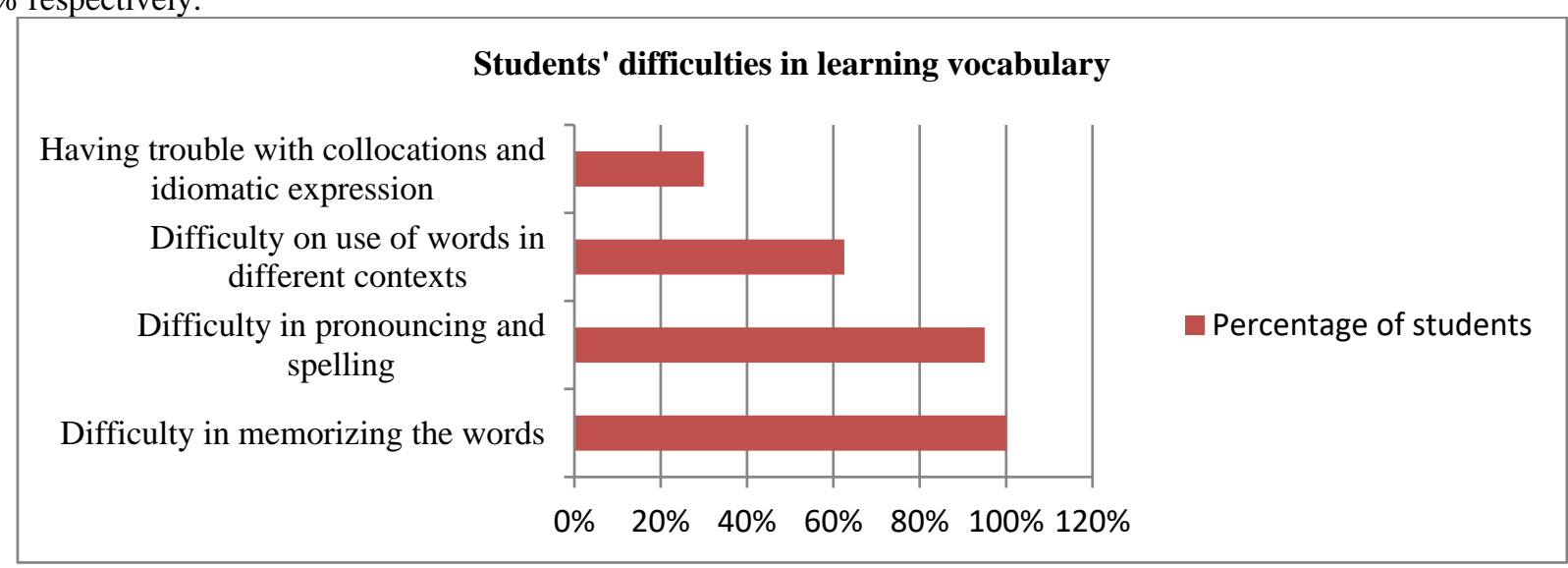

Figure 3. Students' difficulties in learning vocabulary

The figure 3 demonstrates the students' difficulties which they have to face during their vocabulary learning processes. It is not surprising when difficulty in memorizing the words accounted for $100 \%$, and memorizing has been considered as one of the biggest obstructions for students to learn vocabulary in many previous studies. All students have to find the ways and methods to remember a large amount of English vocabulary, and all of words need to be meaningfully stored in long-term memory. Majority students have trouble in pronouncing and spelling correctly. Moreover, over $60 \%$ of students admitted that they could not use words in various contexts although they have learned those words before. Collocations and idiomatic expression are not widely-used among high school students, so just $30 \%$ of participants found them hard to grasp collocations and idioms.

\section{The initial level of students' vocabulary acquisition based on the result of pre-test}

\begin{tabular}{|c|c|c|c|c|c|}
\hline \multirow[t]{2}{*}{ Level } & \multirow{2}{*}{$\begin{array}{l}\text { Scor } \\
\text { e }\end{array}$} & \multicolumn{2}{|c|}{$\begin{array}{l}\text { Experimental } \\
\text { Group }\end{array}$} & \multicolumn{2}{|c|}{ Control Group } \\
\hline & & $\begin{array}{l}\text { Frequen } \\
\text { cy }\end{array}$ & $\begin{array}{l}\text { Perce } \\
\text { nt }(\%)\end{array}$ & $\begin{array}{l}\text { Frequen } \\
\text { cy }\end{array}$ & $\begin{array}{l}\text { Perce } \\
\text { nt }(\%)\end{array}$ \\
\hline $\begin{array}{l}6 \\
\text { (Reaching) }\end{array}$ & $\begin{array}{l}9.5- \\
10 \\
\end{array}$ & 1 & $5 \%$ & 2 & $10 \%$ \\
\hline $\begin{array}{l}5 \\
\text { (Bridging) }\end{array}$ & $\begin{array}{l}8.5- \\
9.4\end{array}$ & 3 & $15 \%$ & 5 & $25 \%$ \\
\hline $\begin{array}{l}4 \\
\text { (Expandin } \\
\text { g) }\end{array}$ & $\begin{array}{l}7.5- \\
8.4\end{array}$ & 7 & $35 \%$ & 6 & $30 \%$ \\
\hline $\begin{array}{l}3 \\
\text { (Developin } \\
\text { g) }\end{array}$ & $\begin{array}{l}6.5- \\
7.4\end{array}$ & 3 & $15 \%$ & 2 & $10 \%$ \\
\hline (Emerging & $\begin{array}{l}5.5- \\
6.4\end{array}$ & 4 & $20 \%$ & 2 & $10 \%$ \\
\hline $\begin{array}{l}1 \\
\text { (Entering) }\end{array}$ & $\begin{array}{l}1- \\
5.4\end{array}$ & 2 & $10 \%$ & 3 & $15 \%$ \\
\hline Total & & 20 & $100 \%$ & 20 & $100 \%$ \\
\hline
\end{tabular}

Table 1. The classification of students' scores in pre-test

The students' scores in pre-test were classified into six levels based on the description of vocabulary assessment rubric named "Holistic rubric" to measure students' vocabulary acquisition adapted from McCarten (2007). Table 1 showed the differences in scores between experimental group and control group. Generally, students' scores in both groups were ranged in all categories. Both groups had the largest number of students classified at "Expanding" level. In experimental group, the percentage of students at reaching level was the least at 5\%, while it represented $10 \%$ in control group. Meanwhile, the number of students at the lowest level in experimental group was less than in control group.

\begin{tabular}{|l|l|l|}
\hline Participants & N & Mean \\
\hline Experimental group & 20 & 7.478 \\
\hline Control group & 20 & 7.605 \\
\hline
\end{tabular}

\section{Table 2. The mean scores of pre-test in experimental group} and control group

The researchers compared the average scores of two groups including experimental and control group. The Table 2 represented that the mean score of control group was bigger than the one of experimental group. However, the gap between two groups was not considerably significant. The figure showed that the initial level of vocabulary competence in both groups was almost the same. Most of them had the fundamental vocabulary to take part in this study, so they could understand the rules of Flashcard games and used Flashcards more effectively.

\section{CONCLUSION}

Based on the aforementioned results and discussions, some conclusions can be drawn. Firstly, it cannot be denied that high school students, particularly $10^{\text {th }}$ graders still had some obstacles in learning vocabulary. Undoubtedly, students need to build a large amount of vocabulary in order to achieve high competency in English. They have to not only memorize thousands of words 
but also have capacity to use words in convey their ideas. Secondly, Flashcard games in this study were utilized to solve the shortage of relevant English input and enhance English teaching and learning. To clarify the effectiveness of using Flashcard games in improving students' vocabulary acquisition, the researchers carried out the experiment in more than 8 weeks. The treatment of using Flashcard games was applied towards 20 participants in experimental group, and then the result was compared to control group. Because of some limitation of the study due to Covid-19 pandemic, the researchers at first found out the initial level of both experimental and control group. The result of pre-test has shown that almost students obtained the average scores, and there was not a significant difference between two groups, so the study could be implemented trustworthily. The researchers also expected to attain the positive results at the end of the research process since there was a significant change in the result of post-test in experimental group.

\section{REFERENCES}

[1] [1] Brown, T. \& Perry, F. (2000). 'A comparison of three learning strategies for ESL vocabulary acquisition.' TESOL Quarterly Vol. 25, No.2 $655-70$.

[2] [2] Baleghizadeh and Ashoori, A. (2011). The Impact of Two Instructional Techniques ()//HDUQHUVII9RFDEXODUl.QRZOHGJH)ODVKFDUGV versus Word Lists. MEXTESOL Journal, 35 (2).

[3] [3] Coady, J. (1997a). 'L2 vocabulary acquisition: A synthesis of the research.' In J. Coady, and T. Huckin, (Eds.), Second Language Vocabulary Acquisition 273-90. Cambridge University Press, Cambridge.

[4] [4] Cross, David. 1991. A Practical Handbook of Language Teaching. London: Cassel.

[5] [5] Cameron, L. 2001. Teaching languages to young learners. Cambridge: Cambridge University Press.

[6] [6] Haycraft, Jhon. 1978. An Introduction to English Language Teaching. England: Longman

[7] [7] Laufer, B. (1992). The development of passive and active vocabulary in a second language: Same or different? Applied Linguistics, 19:2, 255-271.
[8] [8] Leedy, P. \& Ormrod, J. (2001). Practical research: Planning and design (7th ed.). Upper Saddle River, NJ: Merrill Prentice Hall. Thousand Oaks: SAGE Publications.

[9] [9] McCarthy, M.J. (1990). Vocabulary. Oxford: Oxford University Press.

[10] [10] McCarten, J. 2007. Teaching vocabulary: Lessons from the Corpus, Lessons for the classroom. New York: Cambridge University Press.

[11] [11] Nation, I. (2006). How large a vocabulary is needed for reading and listening? The Canadian Modern Language Review/La Revue Canadienne Des Langues Vivantes, 63(1), 59-82. Retrieved from https://doi.org/10.3138/cmlr.63.1.59

[12] [12] Oxford, R.L. \& Scarcella, R.C. (1994). 'Second language vocabulary learning among adults: State of the art in vocabulary instruction.' System 22(2), 231-43

[13] [13] Paul Meara (2008). Vocabulary Acquisition: A Neglected Aspect of Language Learning. Birkbeck College, London.

[14] [14] Paribakht, T.S \& Wesche, M. (1997). 'Vocabulary enhancemen activities and reading for meaning in second language vocabulary acquisition.' In J. Coady, and T. Huckin, (Eds.), Second Language Vocabulary Acquisition 174-200. Cambridge University Press, Cambridge.

[15] [15] Thi Thu Huong Ho (2019). The Effect of Digital Apps on Vietnamese EFL Learners' Receptive Vocabulary Acquisition: A Case Study of Quizlet and Paper Flashcards. Western Sydney University.

[16] [16] Tran Thi Ngoc Yen (2019). Wordlists and Flashcards as EFL vocabulary instructional techniques. Vietnam Journals Online.

[17] [17] Tuite, K., Pavlik, T., Fan, S. B., Robison, T., Jaffe, A., \& Liu, Y. E. (2012). Picard: A creative and social online flashcard learning game. In M. Consalvo, \& S. Feiner (Eds.), Proceedings of the International Conference on the Foundations of Digital Games (pp. 231-234). New York, NY: Association for Computing Machinery.

\section{AUTHORS}

First Author- Pham Thi Kieu Oanh, Foreign languages education faculty, Thai Nguyen University of Education Second Author- Dang Thi Thanh Dung, Foreign languages education faculty, Thai Nguyen University of Education 